\title{
Screening the elderly in the community: controlled trial of dependency surveillance using a questionnaire administered by volunteers
}

\author{
G I Carpenter, G R Demopoulos
}

\begin{abstract}
Objective-To test the benefits of regular surveillance of the elderly at home using an activities of daily living questionnaire administered by volunteers.

Design-Randomised controlled study.

Patients -539 Subjects aged 75 and over from two general practices.

Intervention-All subjects were visited at the beginning and end of the stury by volunteers, who completed a scored activity of daily living questionnaire. The study group were revisited at regular intervals. Individuals with an increase in score $>5$ were referred to their general practitioners. All interactions with social services and health authorities were recorded for both groups.

Main outcome measures-Mortality, activity of daily living score, total number of days in institutions, geriatric and psychogeriatric service contacts, primary health care team contacts, use of community support services.

Results-The study group were admitted to hospital more often than the controls (335 occasions $v 252$ ), but the control group spent $33 \%$ more days in institutions, mainly in long term admissions to residential accommodation. The number of falls reported in the control group doubled (from 17 before the first interview to 36 before the last) and in the study group remained unchanged ( 12 before both interviews). The study group received community support services sooner than the control group. There was no difference between the groups in mortality or activity of daily living score.

Conclusion-Regular visiting of old people at home by non-professional volunteers using a simple activity of daily living questionnaire is a practical way of identifying problems and initiating action for this group.
\end{abstract}

\section{Introduction}

Screening the elderly in the community is a subject that has attracted interest and then lost it as projects have failed to show clear benefits attainable at reasonable cost in time and effort.' This project investigated the value of surveillance of activities of daily living as a method of maintaining health of the elderly at home.

Winchester, Hants SO22 5AA

G I Carpenter, MRCP, consultant geriatrician GR Demopoulos, BSC, research assistant

Correspondence to: Dr Carpenter.

\section{Methods}

The project was a three year prospective randomised controlled study of the effects of dependency surveillance using an activity of daily living questionnaire administered by unskilled volunteers recruited for the project.

A letter of introduction was sent by the general practitioner to all those included in the study. Volunteers visited subjects and completed activity of daily living questionnaires and returned them to one of the authors (GRD). The whole group was visited at the start and end of the project. After the first interviews a list of men and a list of women were prepared, sorted by age. The women were then allocated to a study or control group using random number tables, and their husbands were allocated to the same group. The remaining men were then allocated using random number tables. The study group was revisited at regular intervals. All results were entered into a computer.

Scores derived from the questionnaire completed on subsequent visits were compared with previous scores. Individuals found to have an increase in score of five or more points were referred to their general practitioners for further action as required. Those with specific requests - for example, bath seats-were referred to the relevant agency via the general practice. All referrals were recorded.

\section{THE POPULATION}

Two general practices in Andover agreed to take part in the study. The population was composed of those aged 75 years or more at the start of the project who were living in Andover town, including the surrounding housing estates but excluding the villages. The initial list from the family practitioner committee produced 699 patients. Investigation showed that 602 were potentially traceable, 32 had died, 21 had moved into residential care, 18 had moved out of the area, and 26 could not be traced.

Fifty nine people (11 men and 40 women aged $75-84$ and 3 men and 5 women aged $\geqslant 85$ ) from the final list of 602 refused to take part in the study and four were never at home in spite of frequent attempts to contact them, giving a project population of 539 . Of these, 467 were aged 75-84 (165 men, 302 women) and 72 were aged $\geqslant 85$ ( 23 men, 49 women). There was no significant difference between the two groups in marital state, type of home, or household composition.

The instrument used was the Winchester disability rating scale. It was developed for the project and was a scored questionnaire of 18 items covering reported (as opposed to observed) activities of daily living, including items on, for example, carers, home conditions, and companionship. Copies, with results of reliability and vailidity tests, are available from the authors.

\section{VOLUNTEER INTERVIEWS}

Recruitment of volunteers was most successful through mother and toddler groups and church groups. Recruitment from recognised charities and voluntary bodies was less successful.

Thirty eight volunteers were recruited initially, and 
a further three joined during the project. Six of the volunteers were sixth form students on a one year course; in addition to these six, 11 others withdrew (two for health reasons, one, because she felt unsuited, and eight because they moved from the area or for other reasons). They received a one hour training session when the principles and aims of the project were explained and they were introduced to the questionnaire. Regular four monthly meetings were held to maintain interest and exchange information.

\section{INTERVIEW PATTERN}

When the results of all first interviews had been entered into the computer the authors each reviewed 100 questionnaires, divided them into three disability groups and compared results. The score ranges that each had defined were identical except for a very few cases and were therefore adopted. The three groups identified were those with no significant disability (score 15-20), those with some disability but whose life was not significantly impaired (score 21-32), and those with considerable disability (score $>33$ ). Table I shows the distribution of disability scores in the two groups.

TABLE I - Distribution of disability scores in study and control groups

\begin{tabular}{lccc}
\hline Disability group (and score) & Study group & Control group & Total \\
\hline No disability $(15-20)$ & 160 & 157 & 317 \\
Some disability (21-33) & 98 & 89 & 187 \\
Considerable disability $(>33)$ & 14 & 21 & 35 \\
\hline Total & 272 & 267 & 539 \\
\hline
\end{tabular}

For those with no disability volunteers visited every six months and for those with some disability or severe disability every three months.

\section{RESULTS}

The data presented represent a small proportion of the information collected. All data refer to the total population, not just those completing the project.

The first round of interviews took three months to complete. The total duration of the project from the first to the last interview was therefore 39 months.

A total of 1949 questionnaires were completed during the project; $39 \%$ were completed in $1-15$ minutes, $38 \%$ in $16-30$ minutes, $12 \%$ in $31-45$ minutes, and $11 \%$ in over 45 minutes.

Ninety four people received interventions initiated as a result of the project, 37 receiving more than one intervention. Thirty nine people received an intervention because of a change in their disability score $(10$ of them more than once), 15 because of a request for an aid or service ( 1 of them more than once), 18 because of both a change in score and a request for an aid or service ( 14 of them more than once), and 22 for another reason, including referrals to the housing department or provision of advice (11 of them more than once). Problems identified were mainly non-medical. In 14 cases treatment had already been started and in 17 there was "no treatment available."
SURVIVORS AND MORTALITY

Of the 539 subjects who started the project, 367 $(68 \%)$ completed a final questionnaire, $181(66 \%)$ of the study group and $186(69 \%)$ of the control group. One hundred and twenty people died (66 of the study group and 54 of the controls); 25 people withdrew from the project ( 14 study group and 11 controls); 22 moved out of the area, (11 study group and 11 controls); 2 changed doctor to a different practice; and 3 moved into long term nursing care.

Mortality in the two groups was not significantly different. Mortality was closely related to an increased dependency score in the 75-80 year olds and 80-84 year olds, but this relation was much weaker in the over $85 \mathrm{~s}$ (figure).

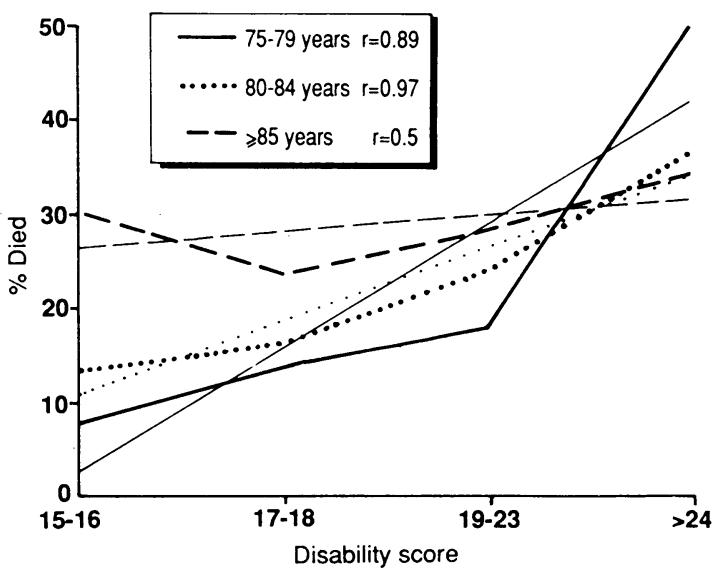

Correlation of mortality with disability score quartile of the Winchester disability rating scale by age group (bold lines). Regression lines are also shown (feint lines)

CHANGE IN ACTIVITIES OF DAILY LIVING SCORE

The mean disability score for the whole population at the start of the project was 20.9. For those completing the project there were significant increases in the mean (SD) disability score in both groups (two tailed paired samples $t$ test $\mathrm{p}<0.01)$ : the score in the study group rose from $19 \cdot 7(4 \cdot 7)$ to $22 \cdot 3(6 \cdot 9)$ and in the control group from $20 \cdot 2(5 \cdot 6)$ to $23 \cdot 1(7 \cdot 9)$. The difference between the groups was not significant.

In the control group 36 falls were reported in the month before the final interview compared with 17 in the month before the first interview (analysis of variance, $p<0.001$ ). In the study group there was no increase in falls, with 12 recorded at both initial and final interviews (analysis of variance between groups, $\mathrm{p}=0 \cdot 1$ at initial interview, $\mathrm{p}<0.05$ at final interview).

\section{ADMISSIONS TO INSTITUTIONS}

One hundred and twenty one people in the study group and 107 controls had a total of 587 admissions (table II). The total number of days spent in institutions was 33\% higher in the control group (16088 days $v$ 12079 ) days. There was a significant difference in the number of people admitted for more than six months (study group 8 , control group $20, \chi_{1}^{2}=4 \cdot 78, p=0 \cdot 03$ ).

TABLE II - Admissions to institutions, mean length of stay, and total length of stay in study and control groups

\begin{tabular}{|c|c|c|c|c|c|c|c|c|}
\hline & \multicolumn{2}{|c|}{ No of admissions (No of indviduals) ${ }^{\star}$} & \multicolumn{2}{|c|}{ Mean (SD) length of stay } & \multicolumn{2}{|c|}{ Admissions lasting $>6$ months } & \multicolumn{2}{|c|}{ Total days in institutions } \\
\hline & Study & Control & Study & Control & Study & Control & Study & Control \\
\hline District general hospital & $144(92)$ & $98(66)$ & $15.9(18.5) \dagger$ & $11 \cdot 7(11 \cdot 0) \dagger$ & 0 & 0 & 2266 & 1148 \\
\hline Community hospital & $107 \quad(61)$ & $68(52)$ & $18.2(23 \cdot 4)$ & $18 \cdot 1(24 \cdot 2)$ & 0 & 0 & 1933 & 1238 \\
\hline Geriatric hospital & $37(16)$ & 15 & $53.9(104 \cdot 1)$ & $108.6(191.5)$ & 2 & 2 & 1992 & 1623 \\
\hline Psychogeriatric hospital & 17 (11) & 21 (11) & $124 \cdot 7(225 \cdot 5)$ & $176 \cdot 2(286 \cdot 9)$ & 2 & 5 & 2121 & 3700 \\
\hline Residential accomodation & 30 (18) & $50(25)$ & $125 \cdot 3(200 \cdot 3)$ & $168 \cdot 3(286 \cdot 8)$ & 4 & 14 & 3752 & 8394 \\
\hline Total & $335(121)$ & $252(107)$ & $36 \cdot 1(105)$ & $63 \cdot 8(171)$ & 8 & 21 & 12064 & 16103 \\
\hline
\end{tabular}

*Some individuals were admitted to more than one type of accommodation.

†Two tailed $t$ test, $\mathrm{p}<0 \cdot 05$ 
Only one person (from the control group) had two admissions lasting more than six months (table II). The pattern of admissions to district general, community, geriatric, and psychogeriatric hospitals and residential accommodation (rest homes and part III accommodation) was significantly different between the groups (table III).

TABLE III-Actual and expected ${ }^{\star}$ numbers of admissions to institutions in study and control groups

\begin{tabular}{|c|c|c|c|c|}
\hline & \multicolumn{2}{|c|}{ Study group } & \multicolumn{2}{|c|}{ Control group } \\
\hline & Actual & Expected & Actual & Expected \\
\hline 1)istrict general hospital & 144 & 138 & 98 & 104 \\
\hline Community hospital & 107 & 100 & 68 & 75 \\
\hline Geriatric hospital & 37 & 30 & 15 & 22 \\
\hline Psychogeriatric hospital & 17 & 22 & 21 & 16 \\
\hline Residential accommodation & 30 & +6 & 50 & 34 \\
\hline Total admissions & 335 & & 252 & \\
\hline
\end{tabular}

$x=20 \cdot 85 ; \mathrm{df}=4 ; \mathrm{p}<0 \cdot 001$

${ }^{\star}$ Expected number of admissions if the admission patterns of the two groups were statistically independent.

DOMICILIARY VISITS, DAY HOSPITAL REFERRALS, SUPPORT SERVICES

There was no significant difference in the rate of referral for domiciliary visits from the geriatric or psychogeriatric services ( 41 and 32 respectively). Neither was there any difference in the rate of referral to the psychogeriatric day hospital (total 12) or for the community psychiatric nursing service (total 13). There were more referrals to the geriatric day hospital in the study group $\left(29 v 14, \chi^{2}, \mathrm{p}<0.05\right)$.

The study group had more referrals for meals on TABLE IV - Number and type of aids provided in study and control groups

\begin{tabular}{lrc}
$\begin{array}{l}\text { Type of. } \\
\text { aid }\end{array}$ & $\begin{array}{c}\text { Study } \\
\text { group }\end{array}$ & $\begin{array}{c}\text { Control } \\
\text { group }\end{array}$ \\
\hline Bed & 7 & 7 \\
Wheekhair & 9 & 12 \\
Other chair & 9 & 3 \\
Toilet aid & 13 & 18 \\
Commode & 17 & 15 \\
Aid for self care & 14 & 14 \\
Bath aid & 41 & 22 \\
Walking aid & 26 & 23 \\
Other & 8 & 6 \\
\hline
\end{tabular}
wheels, (23 $\left.v 12, \chi^{2}, \mathrm{p}=0 \cdot 06\right)$, home helps (29 $\left.v 23\right)$, and aids to daily living (144 $v 118$ ). The type and number of aids provided are shown in table IV. There were few referrals for day centre attendance (20) or for the social services occupational therapist (12).

The pattern of referral for community support services was very different between the two groups in that the referrals were made sooner for those in the study group. The rate of provision to the study group began to exceed that of the control group by the ninth month of the project and continued to exceed it for the following year. During the final year referral rates for aids and services were higher for the control group.

\section{I'RIMARY HEALTH CARE TEAM CONTACTS}

There were 2348 contacts with general practitioners and 264 new referrals to district nurses. There was no significant difference between the groups. Because of staff changes at one of the practices and difficulties in data collection at the other the data were incomplete for the final 15 months of the project. No period analysis could therefore be carried out on these data.

\section{ACCEPTABILITY AND COSTS}

All the interviewers were enthusiastic about the scheme, as were the vast majority of the old people. One hundred and fifty eight of the 180 people remaining in the study group at the end of the project completed a questionnaire asking their opinion of the scheme. Of these, 142 said they wished to continue with the scheme and made many comments such as, "Someone cares," "Someone to call on," "Makes you feel you're not forgotten." Four people were confused about the purpose of the scheme and 13 felt it a waste of time or inappopriate to their needs.

The running costs of the project were low. The only expenses incurred were the costs of printing the questionnaires, salary, and travel expenses for the half time research assistant and purchase of statistical software for the data analysis. The volunteers incurred virtually no costs.

\section{Discussion}

This small scale project has shown that regular visiting of old people at home by non-professional volunteers completing a simple activity of daily living questionnaire is inexpensive, practical, and has an impact on the population visited. The group not visited regularly spent $33 \%$ more days in institutions, most of these in long term admissions to residential accommodation. The group that was visited regularly received community support services sooner and reported no increased incidence of falls at the end of the project. Admissions in the study group were more likely to be to hospitals than were admissions in the control group.

Our method of using volunteers and questionnaires provided a low cost way of recording disability in the community and showed a positive correlation of mortality with increased disability that weakens with increasing age.

The differences between the two groups probably arose as a result of three factors. Firstly, the interviewers provided information about services and aids to daily living, particularly as they became more familiar with available services and aids.

Secondly, those being interviewed may have developed an increased awareness of the remediability of their disability. As they were being asked about abilities in activities of daily living they might have realised that increasing difficulties were potentially remediable rather than irreversible effects of old age, the control group perhaps being resigned to "go into a home" to resolve the problems.

Thirdly, the study group had increased contact with the health services as a result of interventions initiated by the project. Problems identified may have been managed using a geriatric-medical model rather than a social service model.

Previous case-control studies of screening assessment and intervention have shown fewer days in hospital and nursing homes and reduced mortality in the study groups ${ }^{2 .}$ but little impact on health state. ${ }^{3}$ Vetter et al showed reduced mortality, increased service provision. and improved health in an urban community but not in a rural community in a study of regular visiting by health visitors. ${ }^{+}$

Barber and Wallis found that the workload of the primary health care team members rose during the intervention phase and then fell to below the preintervention level in a geriatric screening and assess. ment programme. This effect is supported by the findings of our project in relation to the use of community support services, although the numbers were too small to show an effect in the use of institution based services. Unfortunately the data on use of primary health care services were incomplete.

The project was run in close contact with the general practices but was the responsibility of the geriatric service. A similar programme could be run from a general practice and would be particularly relevant in the light of the new contract's requirement for general practitioners to visit patients aged over 75 at least once a vear.

Regular visiting is most likely to continue when it is structured, both in frequency and in content. The use of a questionnaire such as the Winchester disability rating scale, which is quickly completed, gives a reason for and structure to the visit and ensures that relevant matters are consistently covered. It also gives useful information on dependency and disability in the community for planning purposes. The fact that few medical problems were identified by the project reflects the now widely accepted belief that many of the problems associated with living at home in old age may be remedied by non-medical interventions. The medical problems are generally known and under treatment. ${ }^{\prime \prime}$ 
The next phase of work is to expand the programme across the health district and into sheltered housing. A research programme over five years will include a detailed evaluation of the economic and quality of life implications.

This project was supported by a grant from Wessex Regional Health Authority. We thank the High Street and Adelaide Medical Centre practices; the volunteers who contributed their time and support to the project; and $\mathrm{Mr}$ Paul Fuller of Hampshire social services research department for help with the statistical analysis.
1 Carpenter GI. Screening. In: Linton M, Speller V, Carpenter GI, eds. All of us: strategies for health promotion for old people. Winchester: Wessex Region Health Authority, 1989

2 Hendriksen C, Lund E, Stromgard E. Consequences of assessment and intervention among elderly people: a three year randomised controlled trial. Br.Med f 1984;ii: 1522-4.

3 Tulloch AJ, Moore V. A randomised controlled trial of geriatric screening and surveillance in general practice. F $R$ Coll Gen Pract 1979;29:733-42.

4 Vetter NJ, Jones DA, Victor RV. The effectiveness of health visitors working with the elderly. Cardiff: Welsh National School of Medicine, 1985.

5 Barber JH, Wallis JB. The effects of a system of geriatric screening and assessment on a general practice workload. Health Bulletin 1982;40:125-32. Taylor R, Ford G. The elderly as underconsulters: a critical reappraisal. R Coll Gen Pract 1983;33:699-705.

Ebrahim S, Hedley R, Sheldon $M$. Low levels of ill health among elderly nonconsulters in general practice. Br Med f 1984;289:1273-5.

(Accepted 8 February 1990)

\section{Dunkirk Diary}

\section{Experiences of a battalion medical officer in the retreat to Dunkirk: II}

Richard Doll

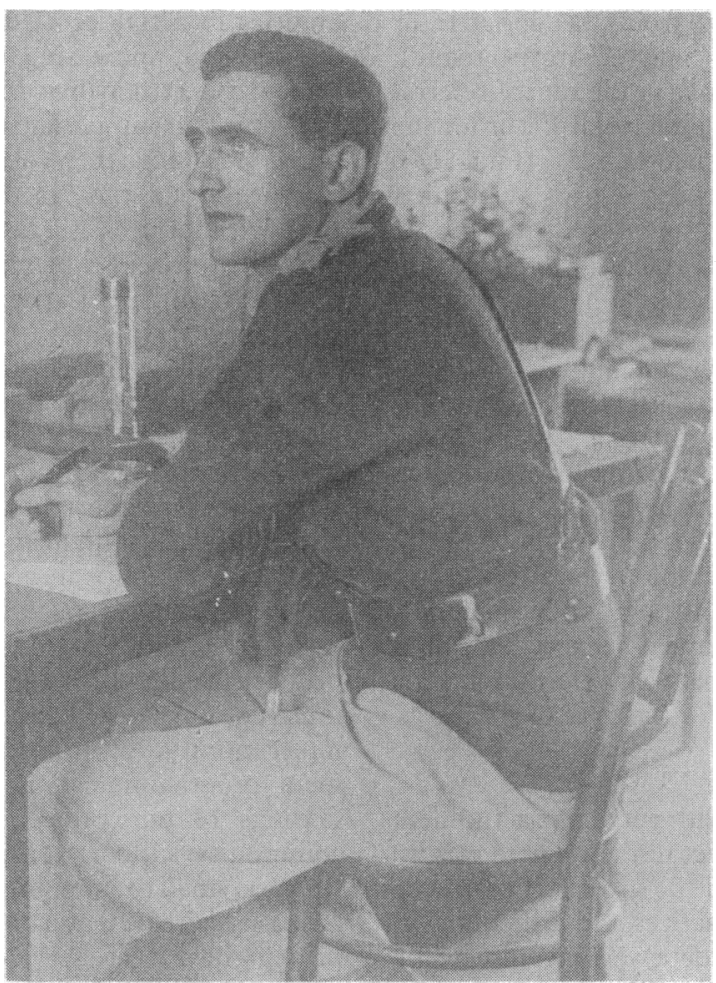

Friday 17 May

It was very quiet today after last night's battle. The position on our front was unchanged, no enemy had crossed the river, and those that had attempted to do so had been dispersed by small arms fire. On our right the third brigade had withdrawn a short distance and on either side the second and third divisions had had severe fighting. That afternoon we learnt that the Germans had gone right through the French on the right of the second division and that their armoured divisions were at Halle, parallel to and about 10 miles inland from Brussels, and had poured on towards France. Quite where they had got to we never learnt till several days later but they must have been down by Cambrai by the time we began to withdraw. We were ordered to deny our forward defence lines to the enemy till 2130 and then to fall back to behind Brussels, where the second and third brigades would pass through the first brigade, which had been held in divisional reserve.
In the time available we were unable to get any transport up from echelon B and so had to leave everything we could not carry ourselves or on the few trucks available. As we knew we were to march long distances, probably in the sun, most of us left behind greatcoats and packs or haversacks. I carried a few personal belongings in my pack, a haversack full of shell dressings, and the surgical haversack. The stretcher bearers were to carry a haversack of shell dressings each and a stretcher among four of them; my medical orderly carried a large haversack full of cigarettes and chocolate; and my batman carried brandy and a bottle of $60 \%$ Pernod, which he had found in the village. We began to thin out at about 2100 , and I had my first experience of sitting down in the dusk waiting to see companies go past and wondering, if they were a minute or two overdue, if they had taken the wrong route and if the first people to arrive would be Germans. This was an experience often repeated in the next two weeks and one I never enjoyed; of all jobs I should least like that of the Royal Engineers waiting behind to blow the bridge after the last troops have crossed - though one way and another in the course of a retreat all units have their own equally unpleasant tasks.

We marched back along a railway line, which was pitted in places by shell holes and where the Royal Engineers had blown the line, for two hours before we reached the divisional cavalry, which had taken up position in a wood to cover our further retreat.

\section{Saturday 18 May}

We continued marching all night, till by 0500 we were only some five miles in front of Brussels. Here we stopped, taking up a defensive position in the woods on either side of the main road. I tried to get to sleep, but with very little success, for the cold (I had only my gas cape as covering) and the intermittent machinegun fire of our divisional cavalry in contact with the enemy a few miles behind us, made it difficult. At 0800 we started off again and, shortly, entered Brussels.

This march was different from that of a week before. The people watched us silently, and occasionally one or two would hold up their thumbs to encourage us. Nobody ever appeared hostile, rather they seemed sorry for us and even at times came out with water (though not beer and wine as before) for the troops. We looked a miserable lot, unshaven, filthy, marching
Richard Doll, FRS, honorary member and emeritus professor 